DOI: $10.17805 /$ trudy.2018.2.7

\title{
СУЩЕСТВОВАНИЕ ЖЕНЩИНЫ МЕЖДУ МИФОМ (ТРАДИЦИЕЙ) И ЛОГОСОМ (РАЗУМОМ)
}

\author{
М. В. Аристова \\ Современная гуманитарная академия, г. Москва
}

Аннотация: В статье анализируется эволюция представлений о месте женщины в культуре, начиная от мифологических образов.

Текст доклада автора на Всероссийской научной конференции «Культура между Логосом и Мифом: к проблеме бессознательного (к 80-летию А.Э. Воскобойникова)», которая прошла в Московском гуманитарном университете 26-27 октября 2017 года.

Ключевые слова: мифология; женщина; гендер; миф; логос; культура

\section{EXISTENCE OF A WOMAN BETWEEN MYTH (TRADITION) AND LOGOS (MIND)}

\author{
M. V. Aristova \\ Modern University for the Humanities
}

Аннотация: The paper analyses the evolution of ideas about a woman's place in culture, beginning with mythological images.

The text of the author's speech at the All-Russian Scientific Conference "Culture between Logos and Myth: on the Issue of the Unconscious (dedicated to the 80th anniversary of A. E. Voskoboynikov)", which was held at Moscow University for the Humanities on 26-27 October 2017.

Ключевые слова: mythology; woman; gender; myth; logos; culture

Термин «миф», пришедший из древнегреческого языка, как известно, означает сказание, содержащее представления людей о мире, месте человека в нём, о происхождении всего сущего. Миф - это предания, которые периодически появлялись в дописьменном социуме и повествовали о жизни предков, подвигах героев, деяниях богов и духов. Миф представляет собой наиболее раннюю историческую форму осознания окружающей действительности индивидом. Рождающиеся в сознании какого-либо народа образы, имена и повествования призваны были объяснять реальные явления и события, а также социальные нормы. Можно сказать, что миф - это особая концепция, утверждающая определенную систему ценностей и объясняю- 
Научные труды Московского гуманитарного университета 2018 № 2

щая ее появление. У наших далеких предков не было учебников по этике и многотомных справочников, предписывающих тот или иной тип поведения в конкретный момент. Все это до определенной степени заменяла мифология. По А. Ф. Лосеву, для молодого человечества мифология служила тем, чем является для нас сегодня наука. Она объясняла различные явления, устоявшиеся нормы, традиции, значимые события.

Главная функция мифологического мировоззрения не лежит в плоскости познавательной деятельности, и основная его цель состоит в укреплении монолитности общества или его части. Мифологическое мировоззрение выступает как целостный механизм социальной регуляции общества. Его специфика состоит в том, что оно генерируется и воссоздается в новых поколениях не рациональной логикой и историческим опытом предшествующих поколений, а обрывочными картинами мира, носящими сугубо индивидуальный и образный характер. В рамках такой картины, природа, общественные явления отражаются и мотивируются к такому отражению лишь в той степени, насколько возникает потребность у самих людей в этом отражении. Так, в мифе всегда есть присутствие нерасчлененного представления между природой и самим человеком. Социальная значимость этого единства находит свое воплощение в принципах коллективизма, утверждающих, что все в этом мире подвластно, если проблема решается коллективно. Это было особенно важно для выживания человеческого рода в условиях враждебной среды обитания. В мифологии вся жизнь должна стоять на тех постулатах, которые были завещаны предками.

Мифологическое мировоззрение на раннем этапе становления общества характеризуется преимущественно игнорированием причинно-следственных методов описания действительности, в результате чего картина мира предстает только в ее пространственно-временном оформлении (например, в нереальных сроках жизни людей, их перерождении и воскрешении часто в другом качестве и т. д.). Миф не порождает вопросов и проблем и не требует от индивида осмысленно-сознательного отношения к окружающему. Но по мере накопления практических знаний, возникает объективная потребность их систематизации уже на уровне рациональной и теоретической деятельности. Поэтому, мифологическое сознание сначала «растворяется» в религиозном, а затем уступает приоритет философскому, оставаясь, тем не менее, в сознании каждого человека в виде психических представлений обыденного уровня.

Мифы, дошедшие до нас, создавались в эпоху патриархата, который Ф. Энгельс оценивает «как порабощение одного пола другим, как провозглашение неведомого до сих пор во всей предыдущей истории антагонизма полов» (Энгельс, 1948: 212). Для патриархата характерен культ физической 
силы и насилия, которое пронизывает все общество, где женщина рассматривается как объект собственности, лишенный самости и активности, за исключением функции продления рода. Практически все мифы посвящены деяниям и прославлению мужчин. Упоминаемые там женщины незаметны, покорны, заняты деторождением, обслуживанием мужчин, ожиданием их возвращения из военных походов и т.п. Любые проявления женской непокорности трактуются как зло, которое следует немедленно пресечь. Но раз в мифах отражается неудовлетворенность женской части населения, значит, сложившееся положение не было изначальным. И действительно, в некоторых мифах история жизни на земле делится на два периода: эпоху «золотого века» (люди в это время были совершенством) и «профанную» эпоху (нравы полностью испорчены) (Мальцева, Электр. ресурс).

О социальном партнерстве между мужчинами и женщинами в доисторические времена гласят мифы, пересказанные некоторыми античными авторами. В этих мифах не упоминается ни о природном или социальном предназначении человека, ни о приоритете полов в обществе, а наблюдается взаимозависимость и взаимодополняемость одного пола другим. «Золотой век» гармонии описан, например, в знаменитом сказании Гесиода «Труды и дни». Тот же мотив преобладает в пересказанном Платоном тексте о гибели Атлантиды. Он же изложил и загадочную легенду о «тайне пола». Речь шла о первичной андрогинности (целостности) древнего человека, о гармоничном соотношении мужского и женского в одном человеке, в котором будто бы в равной мере уживались оба начала: и женское, и мужское. Лишь грехопадение этого человека повлекло за собой его распад на две половины единой прежде души, которые с тех пор бродят в мировом пространстве, силясь отыскать друг друга и обрести утраченную полноту.

Многие исследователи считают, что патриархальному устройству общества, предшествовала иная форма, которую по аналогии с патриархатом называют матриархатом, наделяя его свойствами патриархата только с противоположным (относительно пола) знаком. Доказательством тому, что матриархат всё же существовал, служат отдельные мифы, например, об амазонках, женщинах-воительницах, которые жили без мужчин и воевали с соседствующими племенами. С мужчинами же они встречались только раз в году для продолжения рода. Всех девочек они оставляли у себя в племени, а мальчиков либо убивали, либо отдавали отцам.

Однако австралийская исследовательница Р. Айслер доказывает, что до патриархата существовало скорее паритетное (равноправное) общество, где права отдельных групп населения не ущемлялись (Айслер, 1993: 18-30). Это партнерство было разрушено с появлением и развитием технологий войны, утвердивших превосходство грубой силы. Существенное отличие 
Научные труды Московского гуманитарного университета 2018 № 2

матриархата от патриархата заключалось в том, что ни о каком ущемлении прав мужчин речи не шло, никаких строгих ограничений на их существование не накладывалось. С научной точки зрения для матриархата (если он существовал, поскольку он был до возникновения письменности) характерны только две особенности: матрилинейность (родство устанавливалось по материнской линии) и матрилокальность (дети жили в материнском клане). По мнению Ф. Энгельса, «к всемирно историческому поражению женского пола привело появление частной собственности, которая повлекла за собой радикальные изменения: формирование системы разделения труда между мужчинами и женщинами; становление патриархальной моногамной семьи с главенством мужчины, что обусловлено необходимостью передачи мужчинами своей собственности в руки кровным, законным сыновьям; и, наконец, к развитию экономической зависимости женщин от мужчин» (Энгельс, 1948: 204). Согласно А. Бебелю, материнское право означало равенство всех, появление отцовского права привело ... к «порабощению женщины» (Бебель, 1959). Однако женщины сдались не без боя, что можно увидеть, исследуя содержания древнегреческих мифов, в которых отражен процесс смены матриархата патриархатом.

Фундаментальные исследования, выполненные в середине XIX в. И. Бахофеном и Л. Морганом, не оставили сомнения в том, что матриархальная культура, базирующаяся на материнской любви, существовала. Материнская любовь безусловна, она всему покровительствует, все укрывает собой, а, поскольку она безусловна, ею нельзя управлять, ее нельзя завоевать. Когда она есть, тот, кого любят, испытывает блаженство, а когда ее нет, он испытывает чувство опустошенности, глубокого отчаяния. На этой стадии мать - наивысшее существо: она и богиня, и властительница, как в семье, так и в обществе. Бахофен считал, что в ходе длительного исторического развития мужчинам удалось победить женщин, подчинить их себе и стать правящей силой в общественной иерархии (Баховен, 1996). Установившийся таким образом патриархальный уклад характеризуется моногамией (по крайней мере, для женщины), властью отца в семье и главенствующей ролью мужчин в иерархическом обществе. Эта патриархальная культура соответствовала устройству общества. На смену богине-матери пришли боги мужского пола, они стали верховными правителями над человеком точно так же, как отец стал верховным правителем в семье. Бахофен показал, что различие между патриархальным и матриархальным укладами намного глубже, чем просто социальное превосходство соответственно мужчины или женщины, что различие здесь - в социальных и этических принципах. В матриархальной культуре главное - кровные узы, связь с землей, для нее характерно пассивное восприятие всех природных явлений. Для патриархального об- 
щества, напротив, характерно соблюдение законов, установленных человеком, преобладание рационального мышления, стремление человека, прилагая усилия, изменять природу. В этом отношении патриархальная культура определенно выше матриархальной.

Однако в других отношениях матриархальный уклад был выше, чем победивший патриархальный. С точки зрения матриархального уклада все люди равны, ибо все они - дети матерей и каждый из них - дитя матери-Земли. Мать одинаково и без всяких условий любит всех своих детей, она любит их за то, что все они ее дети, а не за какие-то особые заслуги или достижения; цель жизни в матриархальной культуре - счастье людей, и нет ничего важнее и достойнее, чем существование человека, его жизнь. В то же время при патриархальном укладе главной добродетелью считается подчинение власти. Вместо принципа равенства здесь - принцип любимого сына и иерархии. Но любовь, рожденная материнством, не только более сердечная, но и более широкая и более всеобщая. Если в отцовском начале заложена ограниченность, то в материнском - всеобщность. В рождающем материнстве берет начало всеобщее сестринство/братство всех людей, осознание и признание которого исчезает с возникновением патриархата. Семья, основанная на отцовском праве, замыкается в себе, становясь обособленным организмом, а семья, основанная на материнском праве, напротив, имеет тот всеобщий характер, из которого исходит все развитие и который отличает материальную жизнь от высшей духовной.

В матриархальных обществах эта сторона материнского начала находит многообразное выражение, и в том числе - даже правовое. На ней основывается тот принцип всеобщей свободы и равенства, который является одной из главных черт матриархальных обществ. Л. Морган даже предположил, что более высокий уровень развития цивилизации будет представлять собой возвращение - на более высоком уровне - принципов свободы, равенства и братства, которые были характерны для древних родов. По мнению Э. Фромма, «матриархат фиксировал общество на узах крови и земли, исповедовал, принципы равенства, неприкосновенности жизни, права всех людей на участие в пользовании дарами природы ... представление о том, что все люди - дети Матери Земли, что все они имеют право на счастье, ... и никто не должен доказывать это право, добиваясь какого-то особого положения в обществе» (Фромм, 2006).Он подчеркивает: «Суть матриархального начала - кровное родство - как фундаментальная и нерушимая связь между людьми, равенство всех людей, ценность человеческой жизни и любви. Суть патриархального начала - в том, что связь между мужем и женой, между тем, кто правит, и тем, кем правят, выше кровных уз. Это принцип порядка и власти, подчинения и иерархии» (там же). 
Научные труды Московского гуманитарного университета 2018 № 2

С появлением строгой соподчинённости одного пола другому переписываются даже некоторые религиозные сочинения. Вот как трансформировались сведения о возникновении первой женщины на Земле. В Бытии (первой книге о сотворении мира) говорится о том, что «сотворил Бог человека по образу Своему, по образу Божьему, сотворил его; мужчину и женщину, сотворил их». Это говорит о равноправном положении женщины и мужчины: Адам был создан не один, Бог сразу сотворил ему жену, о которой впоследствии Библия не упоминает. Эта версия входит во многие апокрифические (то есть не признанные официальной церковью) сочинения. Миф гласит, что Лилит и Адам жили счастливо, пока женщина не захотела равноправия. Она отказалась подчиняться мужу, и поэтому Адам отрекся от своей первой жены. Лилит улетела от Адама и стала супругой Сатаны. Три ангела, посланные Богом, пытались вернуть ее в Эдем, но та отказывалась. Впоследствии Лилит стала демоном, ею, согласно мифам, пугали маленьких детей. Поскольку Лилит не являлась образцом смирения, какого ждёт от женщины патриархатное мировоззрение, официальная христианская церковь предпочитает не вспоминать о ней. Адам, будучи несчастным и одиноким, попросил Бога создать для него новую жену, которая бы уважала, ценила и любила его. Так появилась Ева, созданная из его ребра и не равноправная Адаму.

Некоторые исследователи считают, что мифы возникли в процессе неосознанного творения. Содержание мифов воспринималось «как есть» и никогда не подвергалось сомнению. Эти сказания записывались и передавались из поколения в поколение, благодаря чему мы можем сегодня узнать, как же мыслили наши предки, поскольку мифы отражали тогдашний уровень познаний человека. Мифология являлась некой формой общественного сознания, а также одним из способов понимания природной и социальной действительности, которая отражала взгляды человека на определенном этапе развития. Изменение реальности напрямую влияла на содержание мифа, чтобы поддерживать установившийся уклад, как видно из приведенных выше примеров. Исторически миф как совокупность абсолютных (сакральных) ценностно-мировоззренческих истин, противостоящих отражению повседневных событий, служил для поддержания традиции и непрерывности.

В ходе научного прогресса миф все более превращался в литературное произведение, в своеобразную сказку. Он приобрел уничижительный оттенок, обозначая бесплодное, необоснованное утверждение, лишенное опоры на строгое доказательство или надёжное свидетельство. Однако он отнюдь не исчез из употребления. Более того, в современной культуре России наблюдается процесс ремифологизации, когда мифологическое миро- 
восприятие увеличивает своё влияние в искусстве, политике и даже науке, начинает играть значительную, порой даже определяющую роль. Причем возрождаются самые дремучие воззрения на взаимоотношения полов, из исторической пыли вытаскиваются личности, типа зажиточных князей Петра и Февронии, которые культивируются в качестве образца христианского супружества. Это при том, что они не только не имели своих детей, но и не задумались усыновить/удочерить чужих детей, жили в роскоши, завершили свои дни в монастырях. И с них предлагается брать пример замученным бытом российским матерям, живущим на мизерную зарплату, в неимоверной тесноте, лишенным возможности оказывать детям квалифицированную медицинскую помощь и обеспечить им достойное образование. Как отмечается учёными, в современности реалии мифы имеют не познавательный, а поведенческий характер, как форма знания он утрачивает свою актуальность, однако как побуждение к действию не исчерпали своих возможностей. Правда, сейчас мифологизируется не природа, а социальная и эмоциональная жизнь человека.

Термин «миф» очень долго служил в качестве важнейшего источника сведений о прошлом и совпадал с термином «логос», означающим одновременно и «слово» (высказывание, речь) и «понятие» (суждение, смысл). Оба понятия разошлись по смыслу лишь в V веке до н. э. Движение от мифа к логосу - это перемещение от нечеткого разграничения человеческого «Я» и «не Я» к ясному пониманию этого противостояния, а также различия между предметом и образом, то есть это движение от мироощущения к созерцанию. В связи с многозначностью древнегреческого термина «логос» ниже оно будет использоваться исключительно в своем первоначальном философском значении - «рассуждение» - как в объективном, так и в субъективном смысле, т. е. как слово о каком-либо предмете, так и способность рассуждать вообще.

Позднее под логосом в философии стали понимать всеобщий разум, т. е. универсальный закон, которому подчиняется все в мире, благодаря чему мир становится гармоничным, упорядоченным и соразмерным. Новое учение о логосе имело явно религиозную окраску. Логос выступал здесь выражением определенности и постоянства, а также устанавливал своего рода границы, в рамках которых протекают все изменения и трансформации. Начиная с Декарта и Канта, философия была уверена в том, что разумная способность суждения не детерминирована никакими внешними обстоятельствами, а содержание суждения всегда может быть прояснено с помощью самого же разума. При этом предполагалось, что прогресс познания зависит от дальнейшего углубления анализа разума - главной способности сознания. Под сознанием понимают высшую, свойственную человеку фор- 
Научные труды Московского гуманитарного университета 2018 № 2

му обобщенного отражения объективных устойчивых свойств и закономерностей окружающего мира, в результате чего у человека формируется внутренняя модель внешнего мира и достигается познание, позволяющее преобразовывать окружающую действительность.

Сознание является высшим уровнем психического отражения и саморегуляции жизнедеятельности индивида, что присуще только человеку как общественно-историческому существу. В то же время сознание, выступая как особое свойство психики, осуществляет контроль функционирования и самой психики. С другой стороны, было замечено, что какие-то состояния психики формируются вне контроля со стороны самосознательного «Я» в акте взаимодействия психики с внешним миром. Это свидетельствует о том, что психика шире сознания, в ее пространстве есть содержание, не представленное в сознании. Психическая жизнь, которая совершается без участия сознания, психические явления, состояния и действия, протекающие вне контроля разума, обозначаются понятием бессознательного.

Внимание к сфере бессознательного, т. е. к нерациональной, неподконтрольной разуму сфере сознания стали предметом изучения и понимания на стыке XIX и XX веков. В значительной степени это было связано с изучением многочисленных случаев, когда человек, стремящийся достичь чего-то, не в состоянии этого сделать и в результате впадает в конфликтную ситуацию, ведущую к психическим расстройствам. Поскольку на женщин в условиях патриархата были наложены многочисленные ограничения, у них чаще развивался комплекс неполноценности. Не имея возможности развивать свои способности, не улавливая закономерности окружающего мира, не получая при отсутствии должного образования знания, позволяющего преобразовывать окружающую действительность, сознание большинства женщин не способствовало реализации их жизнедеятельности. Зато, многие бессознательные явления (инстинкты, интуиция, творческое озарение, вдохновение, обиды и оскорбления, вытесненные из сознания, сопровождают женщину в течение всей ее жизни. Бессознательное, как указывает российский философ А. Воскобойников, часто связано с непониманием, а также с неполным или ошибочным пониманием (Воскобойников, 2012). Он же считает, что природное и социальное бытие в большей степени детерминируют в человеке бессознательное, чем сознательное.

Австрийскому психиатру 3. Фрейду, удалось найти способ проникновения в сферу бессознательного с помощью методики, позднее названной психоанализом. Суть её заключается в переводе нежелательных, тревожащих, конфликтных фрагментов бессознательного в сознательное, что позволяет их разрешить. Согласно теории психоанализа личность состоит из бессознательного (Оно), предсознательного (Эго, или Я) и сознательного 
(Супер-эго, или Сверх-Я). Бессознательное представляет собой сексуальные и агрессивные инстинкты, стремящиеся к удовлетворению своих влечений во внешней реальности. Эго способствует приспособлению индивида к реальности, сохраняет информацию об окружающем мире в сознании человека в интересах его жизнедеятельности и самосохранения. Супер-эго является вместилищем моральных норм, запретов и поощрений человека и служит, таким образом, как бы совестью человека. Нормы усваиваются человеком бессознательно в процессе воспитания и поэтому проявляются в человеке как чувство страха, вины и угрызения совести. Если человек может подчинить своему Эго бессознательную энергию, или либидо, как назвал её Фрейд, то происходит её высвобождение, и человек живёт гармоничной жизни. В другом случае, накапливаясь в мускулах тела, эта энергия проявляет свою разрушительную силу и устремляется на внешний мир.

Объявив главным мотивом, определяющим поведение человека, сексуальность, Фрейд фактически создал маскулинно-ориентированную теорию, которая вызвала отторжение даже в среде его учеников и соратников. Так, по ряду оснований покинул ряды психоаналитиков А. Адлер, став основоположником собственной теории, названной им индивидуальной психологией. Во-первых, Адлер считал определяющим поведение человека не сексуальность, как у Фрейда, а стремление к власти. Во-вторых, акцент в исследованиях личности Адлером ставился на социальном окружении человека (Фрейд же уделял наибольшее внимание бессознательному).В-третьих, Адлер объявил Эдипов комплекс фабрикацией, а это полностью противоречило идеям Фрейда. Адлер считал, что на поступки человека влияет не только прошлое (как учил Фрейд), но и будущее, а точнее цель, которую человек хочет достичь в будущем: без ощущения цели всякая деятельность индивида лишается смысла. Покинул Фрейда и второй известный его ученик - К. Г. Юнг, который не принимал положение Фрейда о том, что подавления всегда объясняются сексуальными травмами, и считал, что бессознательное - это не только все самое низшее в человеке, но и самое высшее, например, творчество. Юнг вводит понятие «коллективного бессознательного». Когда человек появляется на свет, он уже наполнен древними образами и архетипами, носителями которых являются мифы.

Следующее поколение последователей Фрейда пыталось соединить его учение с марксизмом. Это, прежде всего, Э. Фромм, объявивший любовь единственным способом разрешения всех проблем человеческого существования. Методом достижения совершенного общества он считает моральное просветительство. Необычную мысль высказал Г. Маркузе, который считал, что культура - это не способ разрешения проблем человеческого бытия, а репрессивный аппарат, направленный против свободы человека, его самых 
Научные труды Московского гуманитарного университета 2018 № 2

разнообразных влечений и регулирующих их принципов удовольствия. Таким образом, история развития идей 3. Фрейда показала взаимосвязь духа человека и его бытия. Дальнейшие исследования такой сферы как бессознательное так или иначе обернулись идеями реформации общества.

Особые отношения сложились у психоанализа с феминизмом. С одной стороны, Фрейд подвергался критике за тезисы о женщине как о кастрированном мужчине, об ощущении женщиной своей неполноценности, о биологическом детерминизме. Фрейд рассматривал женщину как зависимую, иррациональную, эмоциональную, пассивную, мазохистскую. В феминисткой теории и практике апелляция к бессознательному, характерная для психоанализа, считалась инструментом утверждения женского подчиненного положения в обществе (Феминизм ..., Электр. ресурс).

Критически относились к психоанализу такие феминистские теоретики, как Б. Фридан, С. Файерстоун К. Миллет. С другой стороны, одновременно признавалось открытие Фрейдом ранее табуированных тем сексуальности, существенное влияние Фрейда на культуру в целом. Феминизм в психоаналитической интерпретации - это отнесение мужской и женской гендерной идентичности к бессознательному, акцент на отношении между матерью и ребенком. Психоанализ понимался феминистками как метод и теория, направленные на исследование того, как человек развивает и использует свои бессознательные фантазии и как он конструирует и реконструирует свои прошлые ощущения в настоящем. Феминистская теория использовала психоанализ в поисках ответа на вопрос о глубинных причинах гендерного неравенства в обществе, пытаясь выявить те пласты бессознательного, эмоционального, сексуального, которые существуют у всех людей. Представителями психоаналитического феминизма являются Л. Иригарэй, Дж. Митчелл, Н. Ходоров, Д. Диннерстайн, К. Гиллиган др.

В психоаналитическом феминизме выделяют направление объектных отношений и межличностное направление (англо-американский подход) и лаканистов (французский подход). Теория объектных отношений позволяет рассмотреть гендерные отношения родительства (Королева, 2013). Диннерстайн указывает, что ребенок вырастает в симбиотической зависимости от матери и потом взрослый мужчина стремится подчинить себе природу и женщину, чтобы не воспроизводить ощущение зависимости. Основные гендерные различия и их иерархичность основаны на латентном страхе и проистекают из того, что первичное воспитание осуществляет только женщина. Ходоров считала, что изменить иерархию гендерных отношений можно, только если оба родителя на равных будут участвовать в «материнстве». Однако из отношений с матерью она выводила не страх, а интимность; взрослые мужчины ищут не разрыва с матерью, а хотя бы ча- 
стичного возврата к симбиозу, и данное стремление подсознательно влияет на отношения с представительницей другого пола. Ходоров рассматривала материнство как главную причину мужской доминации. Во всех обществах процесс материнства осуществляется женщиной, этот факт влияет на эмоции, психофизиологию, межперсональные отношения.

Второе направление феминистского психоанализа связано с именем Ж. Лакана. В отличие от рассмотрения объектных отношений, здесь в центр внимания помещается лингвистическое структурирование сексуальности. Это направление ориентируется на текстуальный анализ и скептически относится к эмпирической реальности. Гиллиган утверждала, что мужчины и женщины имеют разную этику: этику справедливости и этику заботы. Мужская ответственность проистекает из правил, из понимания справедливости, из автономности человеческого существования, а женская - из желаний людей, потребностей и интересов, из осознания себя во взаимодействии с другими людьми. Женщины исходят из конкретных условий, мужчины - из абстрактных. Значимость психоаналитического феминизма для социальной теории заключается в привлечении внимания к социальной природе не только отцовства, но и материнства, постановке проблемы воспитания (особенно - женщинами женщин).

В заключение хотелось бы подчеркнуть, что если сознательное, тесно связанное с разумом (логосом), в течение тысячелетий скорее являлось прерогативой образованной мужской части населения, то бессознательное - скорее женской (как раз в связи с недостаточностью образования). Знаменитое презрительное «женская логика» отражает это состояние. Но ХХиХХІвека, включив женщин в систему общечеловеческого образования, заставили по иному взглянуть на «женскую логику». Более того, многие ценности женского мира приобрели важность и для мужской половины человечества, а особенности устройства мозга у женщин и мужчин объяснили не только причины их недопонимания, но поставили под сомнения целесообразность введения в практику социальной жизни исключительно мужских канонов существования. Ярким примером этого является изменение аксиологии таких понятий как космос и хаос, первое из которых традиционно связывается с мужским, а второе - с женским началом. Именно космос как строгое упорядочивание породил иерархическую структуру, которая пронизала все сферы человеческой деятельности (семью, армию, общественное производство, управление государством и его институтами, церковь).Даже в науке прямолинейный эволюционный путь развития считался незыблемым, а однокорневая (одностержневая) картина развития мира не подвергалась сомнению. Однако в наше время некоторые явления, изучаемые современной наукой, противоречат всеобщей однонаправлен- 
ности. Фактически произошло снижение статуса идеи прогресса как линейного процесса и вместо космоцентричного образа мира-корня возник образ хаосмоса (Хаосмос, Электр. ресурс). В 1976 в философию постмодерна Ж. Делезом и Ф. Гваттари было введено понятие «ризома» (фр. rhizome корневище, клубень). Ризома устроенатак, что в ней нет центра, периферии и выхода, отсюда потенциально она безгранична. Она фиксирует принципиально внеструктурный и нелинейный способ организации целостности. Ризома может развиваться куда угодно и принимать любые конфигурации. Как утверждают авторы этого термина: «... мир потерял свой стержень». Ризоморфные среды обладают имманентным креативным потенциалом самоорганизации, и в этом отношении могут быть оценены не как кибернетические (подчиненные командам «центра»), но как синергетические (от греч. «совместнодействующие»).

\section{СПИСОК ЛИТЕРАТУРЫ}

Айслер, Р. (1993) Чаша и клинок / пер. с англ. М.: Древо жизни.

Бахофен, И. (1996) Материнское право // Классики мирового религиоведения: антология. М.: Канон+. С. 216-268.

Бебель, А. (1959) Женщина и социализм. М.: Госполитиздат.

Воронина, О.А. (2004) Феминизм и гендерное равенство. М.: Эдиториал.

Воскобойников, А. Э. (2012) Бессознательное и сознательное в уединении и на миру // Знание. Понимание. Умение. № 2. С. 119-125.

Воскобойников, А. Э. (1997) Бессознательное и сознательное в человеке. М.: Институт молодежи.

Королева, Т.А. (2013) Женское движение: генезис и эволюция // Вестник Томского государственного университета № 368. С. 44-50.

Мальцева, И. Философия и мифология: сходства и различия[Электронный ресурс] // FB.ru. URL: http://fb.ru/article/38447/filosofiya-i-mifologiyashodstva-i-razlichiya (дата обращения: 12.09.2017).

Феминизм психоаналитический [Электронный ресурс] // Словарь гендерных терминов. URL: http://a-z-gender.net/feminizm-psixoanaliticheskij. html (дата обращения: 12.09.2017).

Фромм, Э. (2006) Искусство любить. СПб. : Азбука-Классика.

Хаосмос [Электронный ресурс] // Национальная философская энциклопедия. URL: http://terme.ru/termin/haosmos.html(дата обращения: 12.09.2017).

Энгельс, Ф. (1948) Происхождение семьи, частной собственности и государства // К.Маркс, Ф.Энгельс. Избранные произведения. Т. 2. М.: Политиздат.

Дата поступления: 12.12.2017 г. 
Аристова Марина Вадимовна - доктор философских наук, кандидат технических наук, профессор; профессор кафедры философии Современной гуманитарной академии, г. Москва. Адрес: 109029. Россия, Москва, Нижегородская улица, 32, стр. 6. Эл. адрес: avotsira@yandex.ru

Aristova Marina Vadimovna, Doctor of Philosophy, Candidate of Technical Sciences, Professor; Professor of Philosophy Department, Modern University for the Humanities. Postal address: 32/6, Nizhegorodskaya Str., Moscow, 109029, Russia. E-mail: avotsira@yandex.ru

\section{Для цитирования:}

Аристова М. В. Существование женщины между мифом (традицией) и логосом (разумом) [Электронный ресурс] // Научные труды Московского гуманитарного университета. 2018. №2. URL: http://journals.mosgu.ru/trudy/ article/view/694 (дата обращения: дд.мм.гг.). DOI: 10.17805/trudy.2018.2.7 